\title{
Grass pollen surface ornamentation: a review of morphotypes and taxonomic utility
}

\author{
Luke Mander ${ }^{*}$ \& Surangi W. Punyasena ${ }^{2}$ \\ ${ }^{1}$ Department of Environment, Earth and Ecosystems, The Open University, Milton Keynes, Buckinghamshire, MK7 6AA, UK \\ ${ }^{2}$ Department of Plant Biology, University of Illinois, 505 South Goodwin Avenue, Urbana, Illinois, 61801, USA \\ *Correspondence: Luke.Mander@Gmail.com
}

\begin{abstract}
The classification of grass pollen is a classic problem in palynology. One approach to this problem is to image grass pollen using scanning electron microscopy (SEM) and to construct morphotypes on the basis of surface ornamentation patterns. In this paper, we construct a database of published SEM images of grass pollen surface ornamentation and use this database to review the status and utility of grass pollen morphotypes. Very little SEM data on grass pollen surface ornamentation have been collected. There are more SEM data on the pollen of species from larger subfamilies such as the Pooideae, but there are no SEM data on the pollen of relatively small subfamilies or the early-diverging APP clade of grasses. The available data support the following six morphotypes: the Hordeum-type, Triticum-type, Avena-type, Setaria-type, Pariana-type and Stipa-type. The phylogenetic distribution of these morphotypes cannot be assessed reliably with the available data, but the Pariana and Stipa types are apparently restricted to the BEP clade. We suggest that fossil grass pollen grains could be classified using these morphotypes and that this could be a means of generating useful evolutionary and palaeoecological information from the grass pollen fossil record.
\end{abstract}

Keywords: Poaceae; grass; pollen; phylogeny; taxonomy

Supplementary material: Our database of grass pollen surface ornamentation is available at https://doi.org/10.6084/m9. figshare.c. 2134356

Received 14 September 2015; accepted 29 October 2015

Grass pollen is remarkably similar throughout Poaceae (the grass family) and is spheroidal with a single pore that is usually, but not always (Skvarla et al. 2003), surrounded by an annulus. When viewed using transmitted light microscopy with brightfield illumination, which is the standard microscopy technique in palynology (Sivaguru et al. 2012), grass pollen grains have a psilate to faint scabrate surface ornamentation (Wodehouse 1935; Fægri et al. 1992; Beug 2004). When viewed using scanning electron microscopy (SEM), however, grass pollen grains are characterized by diverse and intricate surface ornamentation patterns (see Mander \& Punyasena (2014, p. 939) for a comparison of light microscopy and SEM images of grass pollen).

Palynologists have made several attempts to use surface ornamentation patterns to classify grass pollen. These include recent efforts to quantify the complexity of these patterns using computational image analysis (Mander et al. 2013), and the development of grass pollen morphotypes that describe grass pollen surface ornamentation using descriptive terminology (e.g. Köhler \& Lange 1979). However, attempts to classify grass pollen grains using surface ornamentation patterns have been blighted by concerns about the degree to which these patterns reflect grass phylogeny. For example, Kellogg (2015) has pointed out that the morphological groups produced by the computational measures of grass pollen sculptural element size and density developed by Mander et al. (2013) do not correlate with phylogeny, and Page (1978, p. 314) has commented that the 'overall taxonomic significance of sexine pattern in grass pollen is very limited'.

Poaceae is a large plant family and currently contains 11157 species (GPWG 2012). A recently published molecular phylogeny of grasses (GPWG 2012) provides clarification on the evolutionary relationships of the 13 subfamilies that are contained within Poaceae and, in this paper, we use this to review current understanding of the phylogenetic distribution and taxonomic utility of grass pollen surface ornamentation. We focus our attention on grass pollen morphotypes (e.g. Köhler \& Lange 1979) and aim to investigate the following questions: (1) how much SEM data have been collected on grass pollen surface ornamentation? (2) How are the grass pollen morphotypes distributed among the subfamilies of Poaceae?

\section{Database construction}

We searched the literature and constructed a database of published SEM images of grass pollen surface ornamentation. This literature included SEM surveys of taxa from several different subfamilies within Poaceae (Watson \& Bell 1975; Page 1978; Köhler \& Lange 1979; Perveen \& Qaiser 2012; Mander et al. 2013), focused studies of a single species (Datta \& Chaturvedi 2004) or subfamily (Andersen \& Bertelsen 1972; Grant 1972; Peltre et al. 1987; Liu et al. 2004) and isolated SEM images published as part of other morphological work (Skvarla et al. 2003; Sivaguru et al. 2012). We also include images from the PalDat pollen image database (http://paldat.org), with the understanding that the broader palynological community contributed these images and that their taxonomic provenance is subject to greater uncertainty. Each SEM image in these publications was visually inspected and only those images in which the surface ornamentation was clear and not masked by folding of the exine, poor illumination or deposits on the surface of the pollen grain were included in our database. Each grass taxon in the database was assigned to a Poaceae subfamily using A World-Wide Phylogenetic Classification of Poaceae (available via http://www.tropicos.org; published as Soreng $(2000,2001)$ and Soreng et al. (2015)).

Each SEM image in this database was grouped into one of the six morphotypes shown in Figure 1. Four of these, the Hordeum-type, Triticum-type, Avena-type and Setaria-type, are morphotypes that 

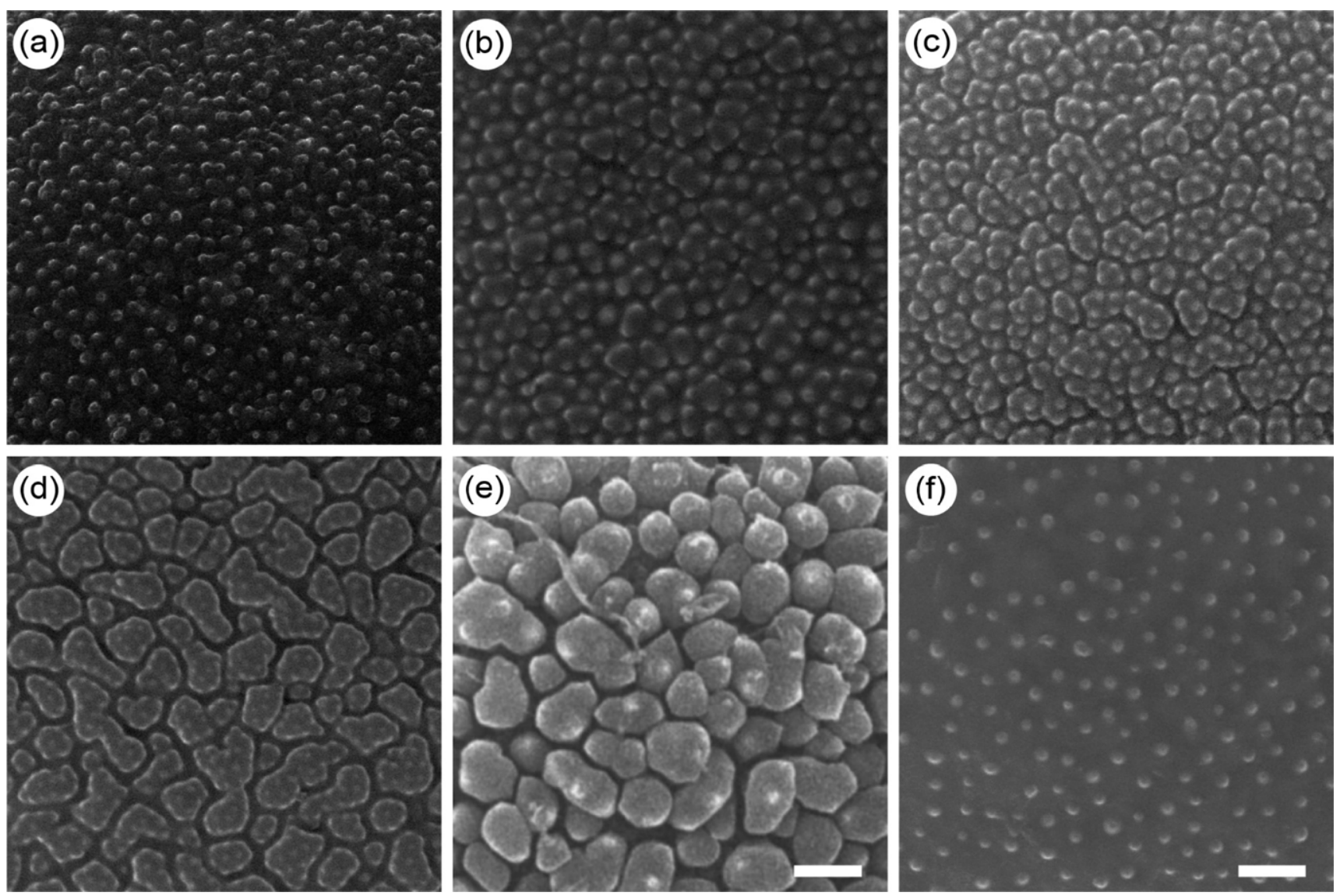

Fig. 1. Thumbnails showing examples of (a) the Hordeum-type, (b) Triticum-type, (c) Avena-type, (d) Setaria-type, (e) Pariana-type and (f) Stipa-type. Taxa shown in these thumbnails are as follows: (a) Agropyron repens, (b) Triodia basedowii, (c) Oryza sativa, (d) Oplismenus hirtellus, (e) Pariana argentea and (f) Stipa tenuifolia. (a)-(d) and (f) Same scale; scale bar $1 \mu \mathrm{m}$. (e) Reproduced with permission from Skvarla et al. (2003, fig. 2); scale bar $1 \mu \mathrm{m}$.

have been established during previous work (Köhler \& Lange 1979). The Hordeum-type 'is characterised by single detached spinules generally not grouped in [areolae]' (Köhler \& Lange 1979, p. 134) (Fig. 1a). The Triticum-type 'is characterised by small [areolae] bearing only one to three, rarely more, spinules' (Köhler \& Lange 1979, p. 137) (Fig. 1b). The Avena-type 'has larger irregularly polygonal or elongate [areolae] studded with several, [1-10] spinules' (Köhler \& Lange 1979, p. 137) (Fig. 1c). The Setaria-type 'is characterised by extensive field-like [areolae] of irregularly polygonal outlines. Their bulging surface is studded with very small pointed spinules' (Köhler \& Lange 1979, p. 139) (Fig. 1d). In these descriptions, the term 'areolae' replaces 'insulae', following Punt et al. (2007).

To these four established morphotypes we add the Pariana-type and the Stipa-type. The Pariana-type is characterized by 'fused and spinulose areolate elements grouped into irregular islands interspersed with globular/granular exine particles approximately 0.25 $\mu \mathrm{m}$ in diameter' (Skvarla et al. 2003, p. 925) (Fig. 1e), while the Stipa-type is characterized by simple scabrate ornamentation that lacks areolae and has sparsely distributed granula (Fig. 1f). Our database is summarized in Table 1.

\section{SEM data and the taxonomic utility of grass pollen morphotypes}

In our database, there are SEM data on the surface ornamentation of the pollen of 99 species of grass. This represents $0.89 \%$ of the 11157 grass species that are currently recognized (GPWG 2012) and there are SEM data on pollen surface ornamentation for just six of the 13 subfamilies within Poaceae (Table 1). There is a positive relationship between the species richness of each subfamily and the number of species with an SEM record of their surface ornamentation (Fig. 2). Larger subfamilies have the most species with an SEM record of their pollen surface ornamentation, whereas smaller subfamilies have received considerably less attention (Fig. 2).

The Poaceae subfamilies are traditionally grouped into three clades (Table 1). There are no SEM data on the pollen of the early diverging APP clade of grasses, which consists of three small subfamilies and contains a total of 28 species (Fig. 3). In the BEP clade, which contains 5423 species within three subfamilies that each exclusively use the C3 photosynthetic pathway (Christin et al. 2013), there are SEM data on the surface ornamentation of one species within the Ehrhartoideae subfamily, six species within the Bambusoideae subfamily and 53 species within the Pooideae subamily (Fig. 3). In the PACMAD clade, which contains a total of 5706 species and includes those that have evolved $\mathrm{C} 4$ photosynthesis (Christin et al. 2013), there are SEM data on the surface ornamentation of 22 species within the Panicoideae subfamily, one species within the Arundinoideae subfamily and 16 species within the Chloridoideae subfamily (Fig. 3). However, there are no SEM data on the pollen of the six species contained in the Centropodia clade or the other three subfamilies within the PACMAD clade (Fig. 3).

There are not enough SEM data to reliably assess the phylogenetic distribution of grass pollen surface ornamentation patterns. However, the available information indicates that the Avena-, Hordeum-, Setaria- and Triticum-types all occur in both the BEP and PACMAD clades (Fig. 3), and this shows that at present these four morphotypes cannot be used to reliably distinguish major groups of grasses (Watson \& Bell 1975; Page 1978; Kellogg 2015). It is intriguing, however, that the Pariana- and Stipa-types are restricted to the BEP clade, and that the Pariana-type only occurs in the Bambusoideae subfamiliy (Fig. 3). Although the data are 
Table 1. A summary of our database showing the morphotypes contained within each subfamily, together with an example taxon and supporting reference for each case

\begin{tabular}{|c|c|c|c|c|}
\hline Clade & Subfamily & Ornamenation types & Example taxon & Reference \\
\hline \multirow[t]{12}{*}{ PACMAD } & \multirow[t]{4}{*}{ Panicoideae } & Avena & Saccharum strictum & Page (1978) \\
\hline & & Hordeum & Zea mays & Watson \& Bell (1975) \\
\hline & & Setaria & Tripsacum dactyloides & Grant (1972) \\
\hline & & Triticum & Panicum miliaceum & Köhler \& Lange (1979) \\
\hline & Micrairoideae & No data & & \\
\hline & Arundinoideae & Avena & Phragmites australis & Watson \& Bell (1975) \\
\hline & Danthonioideae & No data & & \\
\hline & Centropodia clade & No data & & \\
\hline & \multirow[t]{3}{*}{ Chloridoideae } & Hordeum & Spartina townsendii & Liu et al. (2004) \\
\hline & & Setaria & Spartina pectinata & Page (1978) \\
\hline & & Triticum & Triodia basedowii & Mander et al. (2013) \\
\hline & Aristidoideae & No data & & \\
\hline \multirow[t]{11}{*}{ BEP } & Ehrhartoideae & Avena & Oryza sativa & Köhler \& Lange (1979) \\
\hline & \multirow[t]{5}{*}{ Bambusoideae } & Hordeum & Arundinaria alpina & Page (1978) \\
\hline & & Pariana & Pariana argentea & Skvarla et al. (2003) \\
\hline & & Setaria & Olyra micrantha & Page (1978) \\
\hline & & Triticum & Fargesia nitida & http://www.paldat.org \\
\hline & & Stipa & Diandrolyra bicolor & Page (1978) \\
\hline & \multirow[t]{5}{*}{ Pooideae } & Avena & Avena sativa & Köhler \& Lange (1979) \\
\hline & & Hordeum & Bromus inermis & Köhler \& Lange (1979) \\
\hline & & Setaria & Poa compressa & Skvarla et al. (2003) \\
\hline & & Stipa & Stipa tenuifolia & Mander et al. (2013) \\
\hline & & Triticum & Triticum aestivum & Köhler \& Lange (1979) \\
\hline \multirow[t]{3}{*}{ APP } & Puelioideae & No data & & \\
\hline & Pharoideae & No data & & \\
\hline & Anomochlooideae & No data & & \\
\hline
\end{tabular}

extremely limited (only 6 of the 1462 species contained within the Bambusoideae subfamily are present in our database, for example (Fig. 3)), this raises the possibility that a simple morphotyping approach based on SEM images of surface ornamentation might be used to distinguish the BEP clade and the Bambusoideae subfamily in the fossil record and in samples of modern material.

\section{Future work}

In general, very little SEM data on grass pollen surface ornamentation have been acquired (e.g. Fig. 2). The pollen of cereal grasses such as

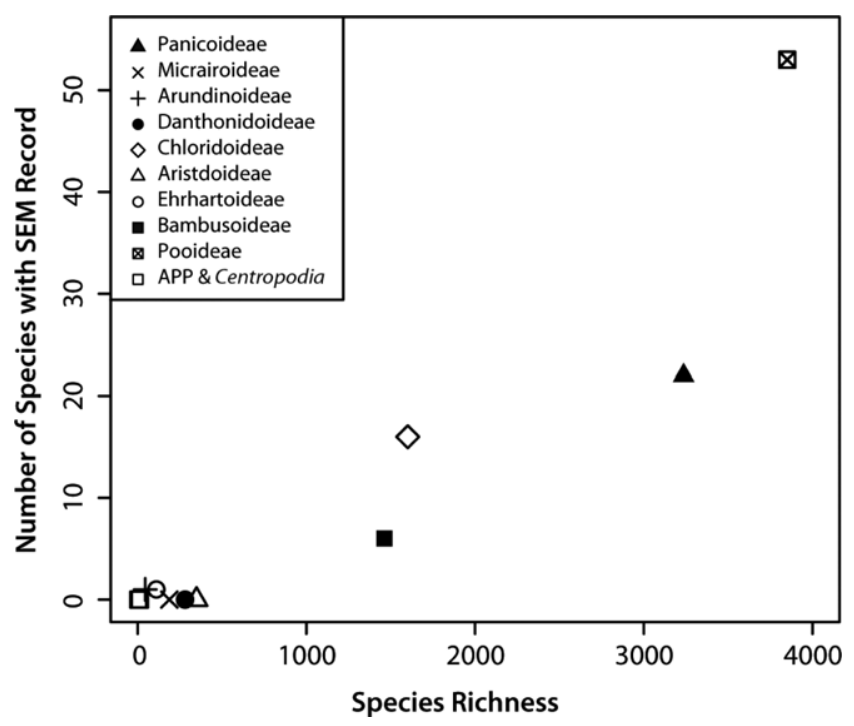

Fig. 2. Scatterplot showing the relationship between the species richness of each subfamily within Poaceae and the number of species with an SEM record of their surface ornamentation. The APP clade of grasses and the Centropodia clade are all represented by a single open square. rye (Secale cereale), wheat (Triticum spp.) and barley (Hordeum vulgare) have received considerable morphological attention in the context of archaeobotanical studies of crop domestication (e.g. Köhler \& Lange 1979), but the pollen morphology of smaller subfamilies, such as the Micrairoideae and the Danthonioideae, is unknown (see Fig. 3). This lack of data is problematic for several reasons. From an evolutionary perspective, it prevents phylogenetic analyses of the mechanisms that have generated the extant diversity of grass pollen form. For example, it is unclear whether the occurrence of the Triticum-type in the Panicoideae, Chloridoideae and Pooideae (Fig. 3) reflects multiple character state gains or the loss, reversal or regaining of characters (e.g. Cronk 2009). In this context, data on the pollen morphology of the early diverging APP clade of grasses would be useful in order to generate comparisons between more primitive and more derived subfamilies. As noted by Kellogg (2015), the lack of data also hinders efforts to examine whether aspects of grass pollen morphology, such as surface ornamentation, have any clear functional significance or whether they correlate with other aspects of biology, such as environment or mode of pollination (e.g. Soderstrom \& Calderón 1971; Skvarla et al. 2003).

The lack of SEM data on grass pollen surface ornamentation also represents an obstacle to the classification of fossil grass pollen in terms of extant taxa (e.g. Lee et al. 2004). This is because workers are currently unable to compare fossil specimens to a database or monograph that displays the full range of natural morphological variation of extant taxa (e.g. Birks \& Birks 1980; Mander \& Punyasena 2014), and the morphological boundaries of grass pollen morphotypes are somewhat unclear as a result (Mander et al. 2013). Additionally, the commonness and rarity of each morphotype is unclear. For example, in the context of the entire Poaceae phylogeny, the Setaria-type occurs 38 times while the Parianatype occurs only twice (Fig. 3). However, there are not enough data at present to reliably indicate whether certain morphotypes are common or rare in each subfamily and this information might help to constrain the affinities of fossil specimens. 


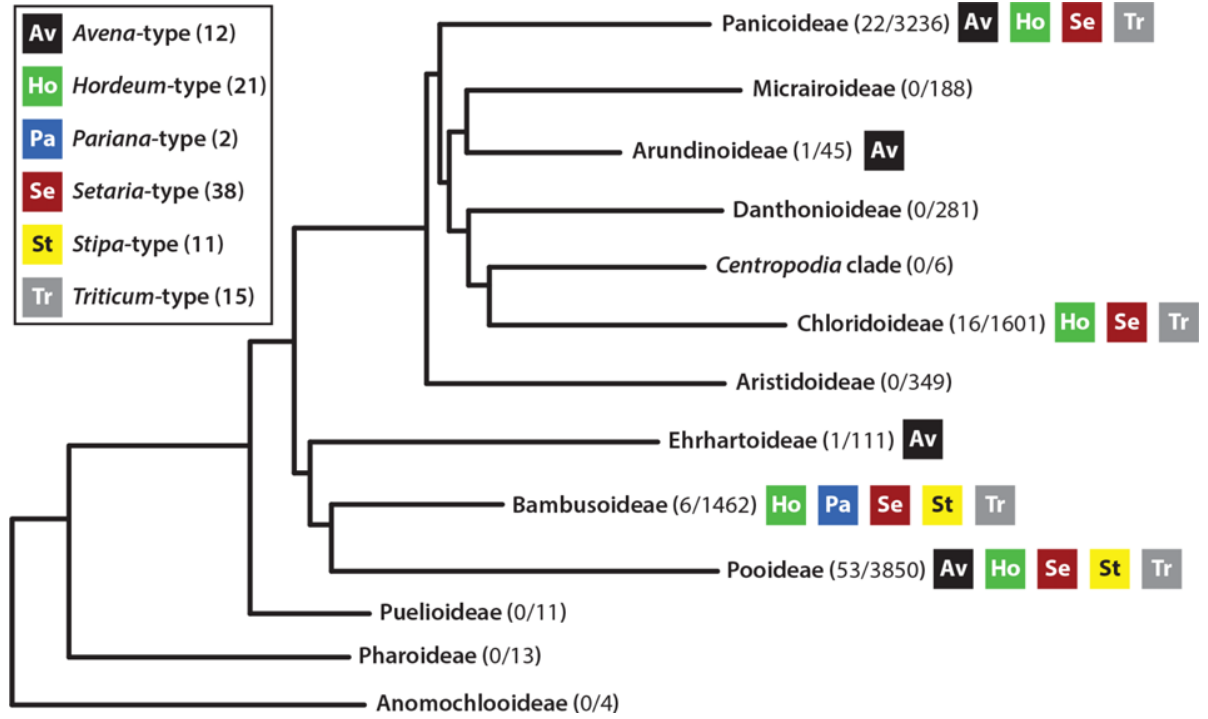

Fig. 3. Phylogenetic tree showing the distribution of grass pollen morphotypes among the subfamilies of Poaceae. Numbers in brackets next to each subfamily show the number of SEM images in our database followed by the number of species within the subfamily. For example, the Panicoideae contains a total of 3236 species and in our database there are published SEM images of the pollen surface ornamentation of 22 species from this subfamily. Numbers in brackets next to each morphotype in the key show the abundance of each morphotype in our database. For example, there are 12 species that are characterized by the Avena-type and 21 species that are characterized by the Hordeum-type. Poaceae phylogeny and subfamily species richness from GPWG (2012).

We remain encouraged by the possibility that grass pollen can play a role in future palaeoecological studies of grasslands. We do note, though, that the spread of morphotypes across the Poaceae phylogeny suggests that this role is likely to be restricted to the generation of raw diversity counts, which could be used to track diversification history and compositional change through time. Such diversity counts could be calibrated by data from fossil phytoliths, which have high taxonomic resolution and allow workers to assess the presence or absence of important subfamilies (Piperno 2006; Strömberg 2011). Owing to the subtlety of grass pollen morphology and, in particular, the surface ornamentation patterns that we have focused on here, we feel that computational approaches (Mander et al. 2013) offer the best chance of generating consistently reproducible classifications (e.g. Mander \& Punyasena 2014). However, the morphotyping approach to grass pollen classification that we have reviewed in this paper could be used to generate broad groupings of morphologically similar grass pollen grains in fossil samples, which could then be classified to finer taxonomic levels using computational methods. Morphotypes generated by human analysts could also be used as a yardstick against which to compare computational classifications (e.g. Mander et al. 2014) and, of course, also represent an archive of ancient biodiversity in their own right.

\section{Acknowledgements and Funding}

We thank Charles Wellman and Wilson Taylor for their comments on the original manuscript of this work.

\section{Scientific editing by Martin Pearce}

\section{References}

Andersen, S.T. \& Bertelsen, F. 1972. Scanning electron microscope studies of pollen of cereals and other grasses. Grana, 12, 79-86.

Beug, H.-J. 2004. Leitfaden de Pollenbestimmung für Mitteleuropa und angrenzende Gebiete. Verlag Dr. Friedrich Pfiel, München.

Birks, H.J.B. \& Birks, H.H. 1980. Quaternary Palaeoecology. Edward Arnold, London.

Christin, P.-A., Osborne, C.P. et al. 2013. Anatomical enablers and the evolution of $\mathrm{C}_{4}$ photosynthesis in grasses. Proceedings of the National Academy of Sciences, USA, 110, 1381-1386.

Cronk, Q.C.B. 2009. Evolution in reverse gear: The molecular basis of loss and reversal. Cold Spring Harbor Symposia on Quantitative Biology, 74, 259-266.

Datta, K. \& Chaturvedi, M. 2004. Pollen morphology of Basmati cultivars (Oryza sativa race Indica) - exine surface ultrastructure. Grana, 43, 89-93.

Fægri, K., Kaland, P.E. \& Krzywinski, K. 1992. Textbook of Pollen Analysis by Knut Fagri \& Johs Iversen. Wiley, Chicester.
GPWG (Grass Phylogeny Working Group II) 2012. New grass phylogeny resolves deep evolutionary relationships and discovers $\mathrm{C}_{4}$ origins. New Phytologist, 193, 304-312.

Grant, C.A. 1972. A scanning electron microscope survey of some Maydeae pollen. Grana, 12, 177-184.

Kellogg, E.A. 2015. Flowering plants, monocots, Poaceae. The Families and Genera of Vascular Plants, 13, Springer International Publishing, Switzerland, 1-265.

Köhler, E. \& Lange, E. 1979. A contribution to distinguishing cereal from wild grass pollen grains by LM and SEM. Grana, 18, 133-140.

Lee, G.-A., Davis, A.M., Smith, D.G. \& McAndrews, J.H. 2004. Identifying fossil wild rice (Zizania) pollen from Cootes Paradise, Ontario: a new approach using scanning electron microscopy. Journal of Archaeological Science, 31, 411-421.

Liu, Q., Zhao, N.-X. \& Hao, G. 2004. Pollen morphology of the Chloridoideae (Graminae). Grana, 43, 238-248.

Mander, L. \& Punyasena, S.W. 2014. On the taxonomic resolution of pollen and spore records of Earth's vegetation. International Journal of Plant Sciences, 175, 931-945.

Mander, L., Li, M., Mio, W., Fowlkes, C.C. \& Punyasena, S.W. 2013. Classification of grass pollen through the quantitative analysis of surface ornamentation and texture. Proceedings of the Royal Society B, 280, 20131905.

Mander, L., Baker, S. et al. 2014. The accuracy and consistency of grass pollen identification by human analysts using electron micrographs of surface ornamentation. Applications in Plant Sciences, 2, 1400031

Page, J.S. 1978. A scanning electron microscope survey of grass pollen. Kew Bulletin, 32, 313-319.

Peltre, G., Cerceau-Larrival, M.T., Hideux, M., Abadie, M. \& David, B. 1987. Scanning and transmission electron microscopy related to immunochemical analysis of grass pollen. Grana, 26, 158-170.

Perveen, A. \& Qaiser, M. 2012. Pollen flora of Pakistan -LXIX. Poacae. Pakiastan Journal of Botany, 44, 747-756.

Piperno, D.R. 2006. Phytoliths: A Comprehensive Guide for Archaeologists and Paleoecologists. AltaMira, New York.

Punt, W., Hoen, P.P., Blackmore, S., Nilsson, S. \& Le Thomas, A. 2007. Glossary of pollen and spore terminology. Review of Palaeobotany and Palynology, $143,1-81$

Sivaguru, M., Mander, L., Fried, G. \& Punyasena, S.W. 2012. Capturing the surface texture and shape of pollen: A comparison of microscopy techniques. PLoS ONE, 7, e39129.

Skvarla, J.J., Rowley, J.R., Hollowell, V.C. \& Chissoe, W.F. 2003. Annulus-pore relationship in Gramineae (Poaceae) pollen: The pore margin of Pariana. American Journal of Botany, 90, 924-930.

Soderstrom, T.R. \& Calderón, C.E. 1971. Insect pollination in tropical rainforest grasses. Biotropica, 3, 1-16.

Soreng, R.J. 2000. Catalogue of New World grasses (Poaceae): I. Subfamilies Anomochlooideae, Bambusoideae, Ehrhartoideae, and Pharoideae. Contributions from the United States National Herbarium, 39.

Soreng, R.J. 2001. Catalogue of New World grasses (Poaceae): II. Subfamily Chloridoideae. Contributions from the United States National Herbarium, $\mathbf{4 1}$

Soreng, R.J., Peterson, P.M. et al. 2015. A worldwide phylogenetic classification of the Poaceae (Gramineae). Journal of Systematics and Evolution, 53, $117-137$.

Strömberg, C.A.E. 2011. Evolution of grasses and grassland ecosystems. Annual Review of Earth and Planetary Sciences, 39, 517-544.

Watson, L. \& Bell, E.M. 1975. A surface-structural study of some taxonomically diverse grass pollens. Australian Journal of Botany, 23, 981-990.

Wodehouse, R.P. 1935. Pollen Grains. McGraw-Hill, New York. 